\title{
Renal transplantation and osteoporosis
}

Annemieke M Boot, Jeroen Nauta, Anita C S Hokken-Koelega, Huibert A P Pols, Maria A J de Ridder, Sabine M P F de Muinck Keizer-Schrama

\begin{abstract}
A cross sectional study assessed the bone mineral density (BMD) of 20 young adult patients who received a renal transplantation in childhood. The BMD of the lumbar spine, mainly trabecular bone, and of the total body, mainly cortical bone, were measured and expressed as an SD score.

Fourteen patients $(70 \%)$ had a BMD SD score of the lumbar spine below -1 , of whom six patients were below -2 . Fifteen patients $(75 \%)$ had a BMD SD score of the total body below -1 , of whom seven patients were below -2 . Both trabecular and cortical bone appeared to be involved in the osteopenic process.

The cumulative dose of prednisone was inversely correlated to both lumbar spine and total body BMD SD score. In a multiple regression analysis the cumulative dose of prednisone appeared to be the only factor with a significant effect on BMD SD score.
\end{abstract}

Most young adult patients who had received a renal transplantation in childhood had moderate to severe osteopenia. Corticosteroid treatment played a major part in the development of osteopenia in these patients.

(Arch Dis Child 1995; 72: 502-506)

Keywords: renal transplantation, osteoporosis, bone mineral density, corticosteroids.

Metabolic bone disease is a known complication in patients with chronic renal failure. Secondary hyperparathyroidism has a central role in the pathogenesis of renal osteodystrophy. ${ }^{1}$ Although successful renal transplantation corrects most metabolic disturbances that cause renal osteodystrophy, osteopenia remains a problem. ${ }^{2-5}$ Bone mass is influenced by renal osteodystrophy, corticosteroid treatment, delayed puberty, and diminished physical activity. $^{2}$

Most studies evaluating bone mass of renal transplant recipients involved patients transplanted in adulthood. ${ }^{235}$ These studies showed a decrease in bone mass after renal transplantation.

As adolescence is a crucial time for the development of bone mass ${ }^{67}$ we evaluated the bone mineral density (BMD) of young adult patients who received their first renal transplantation before the age of 16 years. In addition, we studied the influence of various factors that could affect bone mass such as prednisone treatment, age and pubertal stage at first transplantation, delayed puberty, number of transplantations, and total duration of dialysis.

\section{Patients and methods \\ PATIENTS}

Twenty recipients of renal transplants were studied (13 men and seven women). These patients met the following criteria: first renal transplantation before the age of 16 years and present age between 20 and 30 years. The clinical data of the patients are summarised in table 1. Mean chronological age at the time of the study was 25 years (range 21-29). Mean age at the first transplantation was $12 \cdot 1$ years

Table 1 Clinical data of 20 adult patients after renal transplantation in childhood and results of BMD measurements

Department of Paediatrics, Division of Endocrinology and Nephrology, Sophia Children's Hospital, Medical Schools of Erasmus University, Rotterdam, The Netherlands A M Boot J Nauta

A C S Hokken-Koelega H A P Pols $M$ A J de Ridder S M P F de Muinck Keizer-Schrama

Correspondence to: Dr A M Boot, Sophia Children's Hospital, Divisio of Endocrinology, Dr Molewaterplein 60, 3015 GJ Rotterdam, The Netherlands.

Accepted 14 February 1995

\begin{tabular}{|c|c|c|c|c|c|c|c|c|c|c|}
\hline $\begin{array}{l}\text { Patient } \\
\text { No }\end{array}$ & Sex & $\begin{array}{l}\text { Age } \\
\text { (years) }\end{array}$ & $\begin{array}{l}\text { Primary } \\
\text { renal } \\
\text { disease }^{\star}\end{array}$ & $\begin{array}{l}\text { Age at } \\
\text { first } \\
\text { transplant }\end{array}$ & $\begin{array}{l}\text { No of } \\
\text { transplants }\end{array}$ & $\begin{array}{l}\text { Final } \\
\text { height } \\
S D \\
\text { score }\end{array}$ & $\begin{array}{l}\text { Body } \\
\text { mass } \\
\text { index } \\
\text { SD } \\
\text { score }\end{array}$ & $\begin{array}{l}\text { Cumulative } \\
\text { dose of } \\
\text { prednisone } \\
\text { (mg/kg body } \\
\text { weight) }\end{array}$ & $\begin{array}{l}\text { BMD } \\
\text { lumbar } \\
\text { spine } \\
S D \\
\text { score }\end{array}$ & $\begin{array}{l}\text { BMD } \\
\text { total } \\
\text { body } \\
\text { SD } \\
\text { score }\end{array}$ \\
\hline 1 & F & 28 & CGN & 11.5 & 1 & -0.5 & $-0 \cdot 1$ & 1079 & -1.9 & -0.7 \\
\hline 2 & $\mathbf{M}$ & 26 & CPN & $9 \cdot 7$ & 1 & $-4 \cdot 5$ & $-1 \cdot 1$ & 1558 & -1.8 & $-2 \cdot 4$ \\
\hline 3 & $\mathbf{M}$ & 24 & CHP & $9 \cdot 2$ & 1 & $-2 \cdot 4$ & $2 \cdot 2$ & 818 & -0.4 & 0.0 \\
\hline 4 & $\mathbf{M}$ & 23 & CGN & $7 \cdot 1$ & 1 & -0.9 & -0.8 & 1059 & -1.9 & $-2 \cdot 0$ \\
\hline 5 & $\mathbf{M}$ & 24 & CPN & $7 \cdot 7$ & 1 & -0.9 & 0.0 & 1182 & $-1 \cdot 5$ & $-1 \cdot 7$ \\
\hline 6 & $\mathbf{M}$ & 28 & CGN & $12 \cdot 1$ & 1 & $-1 \cdot 6$ & -0.4 & 1795 & $-3 \cdot 7$ & $-3 \cdot 1$ \\
\hline 7 & $\mathrm{~F}$ & 26 & CHP & $15 \cdot 0$ & 1 & -1.5 & 0.5 & 610 & $0 \cdot 2$ & $-1 \cdot 1$ \\
\hline 8 & $\mathbf{M}$ & 24 & NN & $14 \cdot 5$ & 1 & $-2 \cdot 5$ & $1 \cdot 6$ & 553 & $-2 \cdot 6$ & -1.6 \\
\hline 9 & $\mathbf{M}$ & 23 & CGN & 13.7 & 1 & $0 \cdot 8$ & 0.9 & 483 & $-0 \cdot 7$ & -0.3 \\
\hline 10 & $\mathbf{M}$ & 28 & CGN & $10 \cdot 7$ & 2 & $-5 \cdot 1$ & -0.6 & 2166 & $-4 \cdot 1$ & -3.9 \\
\hline 11 & $\mathbf{M}$ & 26 & CHP & $11 \cdot 6$ & 2 & $-3 \cdot 1$ & -0.8 & 1081 & $-1 \cdot 6$ & $-1 \cdot 8$ \\
\hline 12 & $F$ & 24 & CGN & 10.5 & 2 & $-3 \cdot 6$ & $-1 \cdot 3$ & 1364 & $-2 \cdot 9$ & $-2 \cdot 5$ \\
\hline 13 & $\mathbf{M}$ & 26 & CHP & $15 \cdot 7$ & 2 & $-4 \cdot 6$ & 1.6 & 591 & $-1 \cdot 8$ & $-1 \cdot 0$ \\
\hline 14 & $\mathrm{~F}$ & 28 & MCD & $11 \cdot 3$ & 3 & $-4 \cdot 7$ & -0.2 & 1847 & $-2 \cdot 1$ & $-3 \cdot 3$ \\
\hline 15 & $\mathrm{~F}$ & 29 & CGN & $14 \cdot 5$ & 3 & $-2 \cdot 1$ & $1 \cdot 2$ & 859 & $-0 \cdot 2$ & 0.8 \\
\hline 16 & $M$ & 23 & GR & $12 \cdot 6$ & 3 & $-4 \cdot 2$ & 0.5 & 1186 & $-1 \cdot 7$ & $-1 \cdot 3$ \\
\hline 17 & $\mathbf{M}$ & 27 & CGN & $15 \cdot 1$ & 3 & $-3 \cdot 7$ & -0.3 & 1191 & $-2 \cdot 8$ & $-3 \cdot 5$ \\
\hline 18 & $F$ & 21 & CGN & 11.9 & 3 & $-2 \cdot 8$ & $0 \cdot 1$ & 656 & $-1 \cdot 6$ & -1.9 \\
\hline 19 & $F$ & 25 & CGN & $14 \cdot 1$ & 3 & $0 \cdot 8$ & -0.3 & 706 & $-0 \cdot 2$ & $-0 \cdot 1$ \\
\hline 20 & $\mathbf{M}$ & 26 & MCD & 12.9 & 4 & $-2 \cdot 5$ & $-1 \cdot 1$ & 1952 & -0.4 & $-1 \cdot 7$ \\
\hline
\end{tabular}

*CGN = chronic glomerulonephritis, $\mathrm{CPN}=$ chronic pyelonephritis, $\mathrm{CHP}=$ congenital renal hypoplasia, $\mathrm{NN}=$ nephronophtisis, $\mathrm{MCD}=$ medullary cystic disease, $\mathrm{GR}=$ granulomatous nephritis 
(range $7 \cdot 1-15 \cdot 7)$. The pubertal status at the time of the first transplantation was stage 1 in 12 patients and stage 2 or more in eight patients, according to Tanner and Whitehouse. ${ }^{8}$ Eleven patients started puberty later than the $90 \%$ confidence interval for Dutch children and nine patients started puberty within normal age limits. ${ }^{9}$

The number of transplantations varied from one to four. Eleven patients received more than one renal transplantation. The time since the first transplantation varied from $9 \cdot 1$ to $17 \cdot 8$ years (mean 14.6 years). Three patients did not have a functioning renal transplant at the time of the BMD measurement; two were treated with haemodialysis (patients 14 and 20 in table 1) and one with peritoneal dialysis (patient 11).

The underlying renal disease was chronic glomerulonephritis in 10 patients, congenital renal hypoplasia in four, chronic pyelonephritis in two, medullary cystic disease in two (brother and sister), nephronophtisis in one, and an unclassified granulomatous nephritis in one patient. Seven patients had a congenital renal disease.

\section{MEDICATION}

The standard immunosuppressive drug regimen after renal transplantation included corticosteroids in all patients. Acute rejection episodes were generally treated with three to five alternate day infusions of methylprednisone $(20 \mathrm{mg} / \mathrm{kg})$. At the time of the study 18 patients were on prednisone treatment, four on alternate days and 14 daily, with doses ranging from $2 \mathrm{mg}$ on alternate days to $10 \mathrm{mg}$ daily.

The individual cumulative dose of prednisone/kg body weight was calculated from the time of the first renal transplantation until the BMD measurement. The total duration of prednisone treatment from the first renal transplantation until the BMD measurement, the percentage of time on alternate day prednisone treatment, the number of acute rejection episodes, and the total duration of dialysis before and between renal transplantations were determined.

\section{MEASUREMENTS}

The height was measured by a fixed wall stadiometer and expressed as SD score compared with Dutch sex and age matched reference values. ${ }^{9}$ The body mass index was calculated as weight divided by square height $\left(\mathrm{kg} / \mathrm{m}^{2}\right)$ and was also expressed as the SD score. ${ }^{10}$ The $\mathrm{BMD}$ of the lumbar vertebrae L2-L 4 and of the total body was measured by dual energy $x$ ray absorptiometry (DXA, model DPX-L, Lunar Corporation). ${ }^{11}$ BMD is expressed as $\mathrm{g}$ hydroxyapatite $/ \mathrm{cm}^{2}$. The coefficient of variation (SD) was $1 \cdot 1(0 \cdot 2) \%$. The $\mathrm{BMD}$ results of the lumbar spine and total body were converted to a SD score by comparing the results with a British reference population of sex and age matched young adults, provided by the Lunar Corporation. This reference group was used in the statistical analysis. The British lumbar spine reference data didn't differ from lumbar spine $\mathrm{BMD}$ measurements of a smaller Dutch reference sample. ${ }^{12}$

Approval of the ethics committee of the University Hospital Rotterdam and informed consent of the participants of the study were obtained.

\section{STATISTICAL ANALYSES}

Student's $t$ tests were used to compare intergroup differences. We used simple linear regression analysis to assess a correlation between a continuous factor and BMD SD score. Spearman's rank correlation coefficient was used for covariables that were not normally distributed. Multiple regression analysis (stepwise forward selection) was performed to determine the effect of the factors that had a significant effect in univariate analysis on BMD SD score simultaneously. All tests were performed for both lumbar spine and total body BMD SD score.

\section{Results}

Fourteen patients $(70 \%)$ had a SD score of the BMD of the lumbar spine below -1 , of whom six were below -2 . The mean SD score of the BMD of the lumbar spine of the patients was $-1 \cdot 7$ (range $-4 \cdot 1$ to $0 \cdot 2$ ), which is significant below zero $(p<0.001)$. Fifteen patients $(75 \%)$ had a SD score of the BMD of the total body below -1 , of whom seven patients were below -2 . The mean SD score of the BMD of the total body was -1.6 (range -3.9 to 0.8 ), significant below zero $(\mathrm{p}<0 \cdot 001)$.

The individual results of the 20 patients are summarised in table 1 . The correlation coefficient between BMD SD score of lumbar spine and total body was $0.80(\mathrm{p}<0.001)$. Twelve patients had a BMD SD score below -1 of lumbar spine as well as total body; five patients had a BMD SD score below -2 of both measurements.

The results of simple linear regression analyses are summarised in table 2 . The relation between cumulative dose of prednisone and BMD SD score is illustrated in the figure. The equation for the BMD SD score of the total body was as follows: BMD SD score $=0.337-1.74 \quad(\mathrm{SE} \quad 0.41) \times$ cumulative dose of prednisone $(\mathrm{g} / \mathrm{kg})$, which means that 1 g prednisone $/ \mathrm{kg}$ body weight reduced the SD score of the total body BMD by $1 \cdot 74$. For the lumbar spine BMD SD score this reduction was 1.23 (SE 0.47). There was no correlation between the BMD SD score and the percentage of time on alternate day prednisone treatment. Although the mean final height SD score was markedly reduced (mean $-2 \cdot 5$ ), the mean body mass index SD score did not differ from average (mean $0 \cdot 1)$. Thirteen patients $(65 \%)$ had a height SD score below -2 . There was a significant positive correlation between height SD score and BMD SD score of both measurements and between body mass index SD score and total body BMD SD score.

The patients who received the first renal transplantation at Tanner stage $1(n=12)$ had a lower mean (SE) BMD SD score than the 
Table 2 Correlation between cumulative dose of prednisone, final height, body mass index, and bone mineral density

\begin{tabular}{llc}
\hline & Lumbar spine & Total body \\
BMD & $B M D$ \\
& $S D$ score & $S D$ score \\
\hline Cumulative dose of prednisone & $-0.53^{\star \star}$ & $-0 \cdot 70^{\star \star \star}$ \\
Final height SD score & $0 \cdot 47^{\star}$ & $0.56^{\star \star}$ \\
Body mass index SD score & 0.34 & $0.59^{\star \star}$ \\
\hline${ }^{\star}<<0.05 ;{ }^{\star \star} \mathrm{p}<0.01 ; \star \star \star \mathrm{p}<0.001$. &
\end{tabular}

patients who had started puberty at the time of the first renal transplantation: $-2 \cdot 12(0.30) v$ $-0.93(0.45), \mathrm{p}=0.032$ for total body BMD SD score and $-1.97(0.33) v-1.25(0.41)$ for lumbar spine BMD SD score. There is, however, a significant difference in cumulative dose of prednisone between the two groups.

The 11 patients with delayed puberty had a lower mean (SE) BMD SD score than the nine patients who had started puberty at normal time, $-2.03(0.38)$ and $-1.16(0.38)$ respectively for the total body, $-2.01(0.39)$ and $-1.27(0.32)$ respectively for the lumbar spine, although this difference was not statistically significant.

Factors without significant effect on BMD SD score in a simple linear regression model were: gender, number of transplantations, dialysis at the time of the measurement, age at first renal transplantation, years since the transplantation, duration of dialysis, current prednisone dose, total duration of prednisone treatment, total number of acute rejection episodes, and either acquired or congenital renal disease.

Stepwise forward selection with BMD SD score of the total body or lumbar spine as dependent variable resulted in a model only containing a cumulative dose of prednisone. The pubertal stage at the time of the transplantation, delayed puberty, body mass index SD score, and height SD score had no additional significant effect on BMD SD score.

\section{Discussion}

Our study indicates that most young adult patients who had received a renal transplantation in childhood had moderately to severely decreased BMD. This is the first study with such a long follow up.
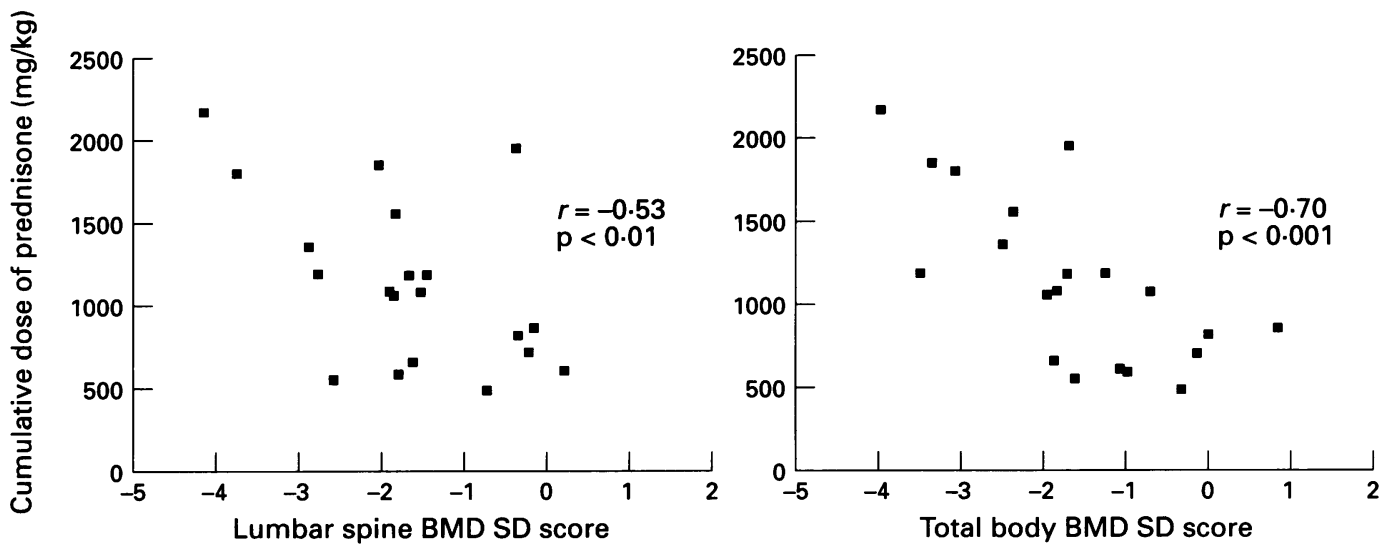

These patients were aged between 20 and 30 years at the time of the study. Healthy individuals have their maximal $\mathrm{BMD}$ at this age. ${ }^{6}$ It has been reported that every $1 \mathrm{SD}$ reduction in bone mass gives an approximate doubling of fracture risk in postmenopausal women. ${ }^{13}$ Differences of 2 SD in bone mass of the lumbar spine, radius, or calcaneus were associated with fourfold to sixfold increases in the risk for vertebral fractures in postmenopausal women. ${ }^{14}$

Thirty per cent of our patients had significant osteopenia of the lumbar spine, BMD more than $2 \mathrm{SD}$ below the mean, and $35 \%$ of the patients had osteopenia of the total body. The lumbar spine is mainly composed of trabecular bone and the bone of the total body is mainly composed of cortical bone $(80 \%$ cortical bone $v$ $20 \%$ trabecular bone). ${ }^{15}$ As corticosteroid induced osteoporosis mainly affects trabecular bone $^{16-19}$ and hyperparathyroidism mainly affects cortical bone, ${ }^{20}$ both these factors appear to be involved in the osteopenic process.

Other studies reported significant bone loss directly after renal transplantation in adult patients. $^{23}$ Progressive loss of BMD of the lumbar spine and femoral neck, measured by DXA, was found in 26 adult patients during the first six months after renal transplantation. ${ }^{2}$ Likewise Julian et al found that the mean BMD of the vertebrae, measured by dual photon absorptiometry, of 20 adult patients had decreased by $8.8 \% 18$ months after transplantation. ${ }^{3}$ The mean spinal BMD was $1.17 \mathrm{SD}$ below normal at the time of transplantation. In this study the BMD of the radial shaft, mostly cortical bone, had increased significantly six months after transplantation from -0.7 to $-0.3 \mathrm{SD}$ score. This may reflect a resolution of secondary hyperparathyroidism. This increase is in contrast to what was found by Kwan et al. ${ }^{2}$ We measured bone mass nine to 17 years after renal transplantation and found that the mean SD score for cortical BMD was $-1 \cdot 6$, significantly below controls.

Significant osteopenia of the radius, ulna, and humerus was measured in 11 of 18 children, aged 4 to 18 years, who had received a renal transplant six months to eight years before, using single photon absorptiometry. ${ }^{4}$

Glucocorticoid induced osteopenia is the result of a number of factors that adversely

Relation between cumulative dose of prednisone and BMD SD score. 
affect calcium homoeostasis. Glucocorticoids decrease bone formation and increase bone resorption, ${ }^{1617}$ mainly of trabecular bone. Intestinal calcium absorption is reduced and renal calcium excretion is increased. We found a significant negative correlation between the cumulative dose of prednisone and both lumbar and total body BMD. Dykman et al found that the effect of long term glucocorticoid treatment in various regimens may result in glucocorticoid induced osteopenia and this effect was cumulative. ${ }^{18}$ Both daily ${ }^{16} 19$ and alternate day ${ }^{21}$ corticosteroid treatment cause bone loss. Chesney et al found that the children receiving daily prednisone treatment had a significantly lower bone mineral content than those receiving alternate day treatment. ${ }^{4}$

In addition to renal osteodystrophy and corticosteroids a delay of puberty may contribute to the development of postrenal transplantation osteopenia. Late puberty is common in children after renal transplantation. ${ }^{22}$ In our study 11 of the 20 patients (55\%) had a late start of puberty and their BMD SD score tended to be lower than the patients who started puberty at a normal age. Bone mass increases with age throughout childhood reaching the peak bone mass by late adolescence or early adulthood. ${ }^{23-26}$ Bone mass accretion during puberty appears to be critical in the development of peak bone mass. ${ }^{27}$ Peak bone mass is regarded as a major determinant of osteoporosis in later life. ${ }^{7}$ Healthy men who had late puberty (the onset of puberty after 15 years of age) had a significant lower BMD of the radius and lumbar spine than men who had their puberty at a normal age. ${ }^{28}$

In $65 \%$ of the patients from this study the final height was more than 2 SD below the mean. This is in accordance with the study of Hokken-Koelega et al showing that in $77 \%$ of the males and $71 \%$ of the females the final height remained below the third centile $(<-1.88 \mathrm{SD}) .^{29}$ These patients received their first renal transplant before the age of 15 .

We found a positive correlation between the height SD score and BMD SD score. Growth may be influenced by the same factors as the bone mass. Some authors described that the method of DXA to measure BMD was influenced by bone size and by calculating the volumetric density, using hypothetical models of the vertebral column, the confounding effect of bone size could be reduced. ${ }^{30}{ }^{31}$ However, Mazess et al demonstrated that the BMD measured by dual photon absorptiometry, which differed from DXA only in the radiation source, correlated well with the quantitative computer scan density of both the total vertebrae $(r=0.89)$ and that of the entire body $(r=0 \cdot 86){ }^{32}$ The quantitative computer scan measures the volumetric density. In a study of total body BMD in normal women, multiple linear regression revealed that height did not have a statistically significant influence on the BMD. ${ }^{33}$ We propose that the correlation between height and BMD cannot be explained by the technique used but that both BMD and height were negatively influenced. Multiple regression analysis revealed that the cumulative dose of prednisone had the most important negative influence on BMD. This may have influenced the final height as well.

We found a significant positive correlation between the body mass index SD score and total body BMD SD score. In healthy adults weight and body mass index had a positive effect on femur and spine $\mathrm{BMD},{ }^{34}$ probably due to load on weight bearing bones.

Our results showed that patients who had received a renal transplantation in childhood had a significantly reduced BMD. In multiple regression analysis only the cumulative dose of prednisone appeared to have a significant effect on BMD. Children who receive a renal transplantation have a highly increased risk of developing osteoporosis. Glucocorticoid sparing immunosuppressive regimens might reduce osteopenia after transplantation.

The authors thank professor W Weimar, Dr P C Chang, and Dr P Kramer for their assistance with patient care and NovoNordisk for financial support.

1 Malluche HH, Monier-Faugere MC. Uremic bone disease: current knowledge, controversial issues and new horizons. Miner Electrolyte Metab 1991; 17: 281-96.

2 Kwan JTC, Almond MK, Evans K, Cunningham J. Changes in total bone mineral content and regional bone mineral density in renal patients following renal transplanmineral density in renal patients following renal tran

3 Julian BA, Laskow DA, Dubovsky J, Dubovsky EV, Curtis JJ, Quarles LD. Rapid loss of vertebral mineral density after renal transplantation. $N$ Engl f Med 1991; 325: 544-50.

4 Chesney RW, Rose PG, Mazess RB. Persistence of diminished bone mineral content following renal transplantation in childhood. Pediatrics 1984; 73: 459-66.

5 Nielsen HE. Bone mineral content in renal transplant patients. Clin Nephrol 1978; 10: 196-200.

6 Ott SM. Bone density in adolescents. $N$ Engl f Med 1991; 325: $1646-7$.

7 Gilsanz V, Gibbens DT, Roe TF, et al. Vertebral bone density in children: effect of puberty. Radiology 1988; 166: density in

8 Tanner JM, Whitehouse RH. Longitudinal standards for height, weight-height, weight-velocity and stages of puberty. Arch Dis Child 1976; 51: 170-9.

9 Roede MJ, Van Wieringen JC. Growth diagrams 1980, the Netherlands. Third nation wide survey. Tijdschrift Sociale Gezondheidszorg 1985; 63 (S): 1-34.

10 Najjar MF, Rowland M. National Center of Health Statistics: anthropometric reference data and prevalence of overweight, United States 1976-80. Vital and health statistics. Series 11 , No 238. Washington, DC: USPHS: DHHS Publication (PHS), 1987: 1-73.

11 Mazess RB, Barden HS, Bisek JP, Hanson J. Dual-energy absorptiometry for total body and regional bone mineral and soft tissue composition. Am $\mathcal{F}$ Clin Nutr 1990; 51: 1106-12.

12 Erdtsieck RJ, Pols HAP, Algra D, Kooy PPM, Birkenhäger JC. Bone mineral density in healthy Dutch women: spine and hip measurement using dual-energy X-ray absorpand hip measurement using dual-energy

13 Cummings SR, Black DM, Nevitt MC, et al. Bone density at various sites for prediction of hip fractures. Lancet 1993; 341: 72-5.

14 Ross PD, Davis JW, Epstein RS, Wasnich RD. Pre-existing fractures and bone mass predict vertebral fracture incidence in women. Ann Intern Med 1991; 114: 919-23.

15 Martin TJ, Kong Wah NG, Nicholson GC. The biology of bone. Baillières Clin Endocrinol Metab 1988; 2: 1.

16 Lukert BP, Raisz LG. Glucocorticoid-induced osteoporosis: pathogenesis and management. Ann Intern Med 1990; 112: 352-64.

17 Reid IR. Pathogenesis and treatment of steroid osteoporosis. Clin Endocrinol (Oxf) 1989; 30: 83-103.

18 Dykman TR, Gluck OS, Murphy WA, Hahn TJ, Hahn BH. Evaluation of factors associated with glucocorticoidinduced osteopenia in patients with rheumatic diseases. Arthritis Rheum 1985; 28: 361-8.

19 Laan RFJM, van Riel PLCM, van de Putte LBA, et al. Low dose of prednisone induces rapid reversible axial bone loss in patients with rheumatoid arthritis. Ann Intern Med in patients with

20 Pfeilschifter J, Siegrist E, Wuster C, Blind E, Ziegler R. Serum levels of intact parathyroid hormone and alkaline phosphatase correlate with cortical and trabecular bone phosphatase correlate with cortical and trabecular bone loss in primary hyperparathyrc

21 Ruegsegger P, Medici TC, Anliker M. Corticosteroidinduced bone loss. A longitudinal study of alternate day therapy in patients with bronchial asthma using quantitative computer tomography. Eur f Clin Pharmacol 1983; 25: 615-20. 
22 Van Diemen-Steenvoorde R, Donckerwolcke RA, Brackel $\mathrm{H}$, Wolf ED, de Jong MCJW. Growth and sexual matura tion in children after kidney transplantation. $\mathcal{F}$ Pediatr tion in children

23 Bonjour J, Theintz G, Buchs B, Slosman D, Rizzoli R Critical years and stages of puberty for spinal and femoral bone mass accumulation during adolescence. $\mathcal{f} \mathrm{Cli}$ Endocrinol Metab 1991; 73: 555-63

24 Gordon CL, Halton JM, Atkinson SA, Webber CE. The contributions of growth and puberty to peak bone mass. Growth Dev Aging 1991; 55: 257-62.

25 Theintz G, Buchs B, Rizzoli R, et al. Longitudinal monitoring of bone mass accumulation in healthy adolescents: evidence for a marked reduction after 16 years of age at the levels of lumbar spine and femoral neck in female subjects. F Clin Endocrinol Metab 1992; 75: 1060-5.

26 Rubin K, Schirduan V, Gendreau P, Sarfarazi M, Mendola Dals $G$. Predictors of axial and peripheral bon $R$, Dalsky G. Predictors of axial and peripheral bone special attention to the role of puberty. $\mathcal{F}$ Pediatr 1993; special attention

27 Ott SM. Attainment of peak bone mass [Editorial]. $f$ Clin Endocrinol Metab 1990; 71: 1082A-C.
28 Finkelstein JS, Neer RM, Biller BMK, Crawford JD, Klibanski A. Osteopenia in men with a history of delayed puberty. $N$ Engl F Med 1992, 326: 600-4.

29 Hokken-Koelega ACS, van Zaal MAE, van Bergen W, et al. Final height and its predictive factors after renal transplantation in childhood. Pediatr Res 1994; 36: 323-8.

30 Kröger H, Kotameini A, Vainio P, Alhava E. Bone densitometry of the spine and femur in children by dual energy x-ray absorptiometry. Bone Miner 1992; 17: 75-85.

31 Carter DR, Bouxsein ML, Marcus R. New approaches for interpreting projected bone densitometry data. 7 Bone Miner Res 1992; 7: 137-45.

32 Mazess RB, Pederson P, Vetter J, Barden HS. Bone densitometry of excised vertebrae; anatomical relationships. Calcif Tissue Int 1991; 48: 380-6.

33 Herd RIM, Blake GM, Parker JC, Ryan PJ, Fogelman I Total body studies in normal British women using dual energy X-ray absorptiometry. Br $\mathcal{f}$ Radiol 1993; 66: energy

34 Felson DT, Zhang Y, Hannan MT, Anderson JJ. Effects of weight and body mass index on bone mineral density in men and women: the Framingham study. $\mathcal{f}$ Bone Miner Res 1993; 8: 567-73. 